\title{
CrimRxiv
}

\section{Strategic Responses to Grand Challenges: Why and How Corporations Build Community Resilience}

Ralph Hamann, Lulamile Makaula, Gina Ziervogel, Clifford Shearing, Alan Zhang

Published on: Jun 21, 2021

DOI: $10.21428 / \mathrm{cb} 6 \mathrm{ab} 371.578 d 9 f 41$

License: Creative Commons Attribution 4.0 International License (CC-BY 4.0). 
